[13] Mazurec, S. I., Kovalyov, S. V., Rudnyk, A. M. (2012). Phytochemical study of the lipophilic fraction from the leaves of ordinary hops. Zaporizhzhia Medical Journal, 72 (3), 96-99.

[14] Marchyshyn, S., Krasulya, N., Kulitska, M., Ostrovska, G. (2011). Investigation of the lipophilic fraction of the herb of the chammeria narrow-gauge. Farmacevtuchnyj chasopys, 1, 18-21.

[15] Sidorov, R. A. (2013). Composition of greasy oils of berry bushes fruits. Moscow, 22.

[16] Pharmaceutical Encyclopedia (2010). Kyiv: MORION, 1632

[17] Poddubny, N. P., Sampiyev, A. M. (2000). Beta-carotene: experience and perspectives in medicine. Krasnodar, 34.

[18] Yakovleva, L. V., Tkachova, O. V., Gladuk, E. V. (2003). Study of the therapeutic effect of the almond ointment on the model of contact turpentine dermatitis in rats. Collection of scientific works of NMAPO named after P. L. Shupyk, 12 (1), 1000-1005.

[19] Happe, M. R., Battafarano, D. F., Dooley, D. P., Rennie, T. A., Murphy, F. T., Casey, T. J., Ward, J. A. (2002). Validation of the Diesse Mini-Ves Erythrocyte Sedimentation Rate (ESR) Analyzer Using the Westergren ESR Method in Patients With Systemic Inflammatory Conditions. American Journal of Clinical Pathology, 118 (1), 14-17. doi: 10.1309/yhyl-8xth-5jm2-43ej

[20] Kamyshnikov, B. C. (2009). Reference book for clinical and biochemical research and laboratory diagnostics. MED press-inform, 920 .

\title{
PARANOID SCHIZOPHRENIA NEGATIVE SYMPTOMS FEATURES IN CASE OF PRESENCE OF MUSICAL EAR
}

\author{
Natalya Kostyuchenko \\ Department of Psychiatry and Psychotherapy \\ Danylo Halytsky Lviv National Medical University \\ 69 Pekarskaya str., Lviv, Ukraine, 79010 \\ n.kostyuchenko@gmail.com \\ Olexander Filts \\ Department of Psychiatry and Psychotherapy \\ Danylo Halytsky Lviv National Medical University \\ 69 Pekarskaya str., Lviv, Ukraine, 79010 \\ filz_uuap@mail.lviv.ua
}

\begin{abstract}
In our work, we propose one of the options for a prognostic criterion, which at the beginning of the disease can provide sufficient evidence to predict the form and severity of negative symptoms in schizophrenia.

Aim. To investigate the influence of the presence of ear on music on the degree of severity of deficiency symptoms in paranoid schizophrenia.

The study was conducted on the basis of the third clinical department of the Lviv Regional Clinical Psychiatric Hospital for the period of 2015. 40 patients with paranoid form of schizophrenia, aged 18 to 35, were examined, of which: group I - 20 patients with advanced ear on music (average age $28.60 \pm 1.01$ years) and group II -20 patients with no ear on music (average age $27.30 \pm$ \pm 1.15 years). The main methods of studying the observation groups were: clinical-psychopathological, pathopsychological, and statistical. The pathopsychological study of the evaluation of negative symptoms was conducted using the "Qualitative Assessment Scale for Positivity, Negative and General Psychopathological Syndromes” (PANSS - Positive and Negative Syndrome Scale), namely, its PANSS-NS subscale. Comparison of the probability of the difference between the average indices of unrelated groups was carried out using the Mann-Whitney method, comparing the relative parameters of the distribution structure by the xi-square criterion.

Analysis of the results of the study shows that in patients with developed ear on music, the level of deficiency symptoms of negative symptoms under the PANSS-NS subclass is 2.2 times lower $(p<0.01)$ than in patients with no developed ear on music: $2.04 \pm 0.14$ against $4.46 \pm 0.17$ points, respectively. Comparing the key indicators of the PANSS-NS subscale in patients with paranoid schizophrenia with advanced ear on music, it was found that the manifestations of "Violations of abstract thinking" (N5 - 2.35 \pm \pm 0.15 points), "Violation of spontaneity and smoothness in the conversation" (N6 - $2.30 \pm 0.15$ points) and "Stereotyped thinking"
\end{abstract}


(N7 - 2.20 \pm 0.16 points). All these negative symptoms were in patients with muscular earache with significantly lower scores: from lack of severity (1 point) to weakness ( 3 points). The lack of expressiveness (1 point) was most common in N4 "Passive-apathy social strangeness “ $-35.00 \pm 10.67 \%$ of patients, very weak severity ( 2 points) - for N1 "Blurred passion" $-75.00 \pm 9.68 \%$ of patients ( $\mathrm{p}<0.05$ with the proportion of negative symptoms 1 and 3 points), weakness ( 3 points) - for N5 $-45.00 \pm 11.12 \%$ of patients $(\mathrm{p}<0.05$ with the proportion of negative symptoms 1 point $)$ The highest proportion $(70.00 \pm 10.25 \%, p<0.05$ with a share of negative symptoms of 6 points) of patients with paranoid schizophrenia without ear on music had a high severity ( 5 points) of rigidity and stereotyping of thinking (N7).

The obtained data prove the influence of the factor of the presence of ear on music on deficit syndrome, as well as on the forms and degree of severity of negative symptoms in paranoid schizophrenia.

Keywords: paranoid schizophrenia, prognosis, psychoacoustics, negative symptoms.

\section{Introduction}

Problems of the forecast in schizophrenia, and in particular - the formation and severity of negative symptoms during its long-term course remains the key to the clinical study of this disease. The prognosis as the quintessence of clinical research (if we take into account the lack of reliable knowledge about the pathogenesis of schizophrenia), underlies the entire strategy of treatment and rehabilitation of patients with severe mental disorders [1,2].

In our work, we propose one of the options for a prognostic criterion, which at the beginning of the disease can provide sufficient evidence to predict the form and severity of negative symptoms in schizophrenia.

Diagnosis of schizophrenia and disorders of the schizophrenic spectrum most often, compared to other mental illness, causes significant diagnostic and expert difficulties [3]. This is due to the pathomorphism of the "classic" clinical picture of the disease, the similarity of a number of symptoms with manifestations of other nosological forms [4]. Of particular importance in preventing diagnostic and expert mistakes in assessing the negative symptoms of schizophrenia are specific research methods, such as qualification scales $[5,6]$. There are a large number of scales to evaluate it. One of the most common is PANSS, which was developed by Keem and co-authors on the basis of the classification of schizophrenia type I and type II (for Crow) in 1980, and which, in essence, is a semi-structured interview with a clinical evaluation, provides a balanced representation of positive, negative and general psychopathological symptoms [7, 8]. This scale is divided into positive, negative and subscale of general psychopathological syndromes [9]. The negative subscale (PANSS-NS) includes seven diagnostic items; each evaluated using the 7-point Likert scale, where higher scores reflect the severity of the symptoms $[10,11]$. Summing points for all seven items gives a global assessment of the negative symptoms $[12,13]$.

The PANSS scale, according to many studies, is characterized by satisfactory psychometric properties: the values of the coefficients of reliability and internal consistency are in the range from 0.60 to 0.83 for the positive, negative and general psychopathological subscale [14, 15], the Kappa index for the negative subscale -0.84 [16]. However, this scale has both strengths and weaknesses, which are due to insufficient content validity, unstable factor structure $[17,18]$.

The results of world research show the scientific expediency and the practical need to use scales for assessing negative symptoms in clinical practice and research. Taking into account current publications on the signs of psychoacoustics in schizophrenia [19,20], as well as our clinical observations of patients with paranoid schizophrenia with advanced ear on music, we conducted studies to prove the connection between the presence of ear on music and the features of the clinical picture of deficiency symptoms, its qualitative composition and degree of severity.

\section{Aim of research}

To investigate the influence of the presence of ear on music on the degree of severity of deficiency symptoms in paranoid schizophrenia. 


\section{Materials and methods}

The study was conducted on the basis of the third clinical department of the Lviv Regional Clinical Psychiatric Hospital for the period of 2015. 40 patients with paranoid form of schizophrenia, aged 18 to 35, were examined and divided into 2 groups: group I - 20 patients with advanced ear on music (average age $28.60 \pm 1.01$ years) and group II -20 patients with no ear on music (average age $27.30 \pm 1.15$ years).

The main methods of studying the observation groups were: clinical-psychopathological, pathopsychological, and statistical. The implementation of the clinico-psychopathological method for the evaluation of negative symptoms was to conduct a structured interview, in which the debut

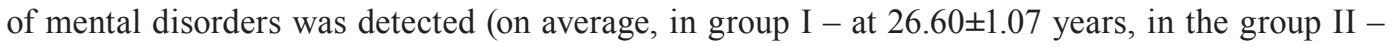
$25.30 \pm 1.47$ years). The pathopsychological study of the evaluation of negative symptoms was conducted using the "Qualitative Assessment Scale for Positivity, Negative and General Psychopathological Syndromes" (PANSS - Positive and Negative Syndrome Scale), namely, its PANSS-NS subscale. The statistical method of the study was to process the obtained results using the analysis of relative (extensive parameters (P)) and average values (arithmetic mean (M)) and their standard errors $\left( \pm \mathrm{m}_{\mathrm{p}}, \pm \mathrm{m}\right)$ [21]. Since the primary data was in the form of rating scales, the comparison of the probability of the difference between the mean of unrelated groups was carried out using the Mann-Whitney method. The comparisons of the relative indicators of the distribution structure were made according to the xi-square criterion.

\section{Results}

Analysis of the results of the study shows that in patients with developed ear on music, the level of deficiency symptoms of negative symptoms in the subscale is 2.2 times lower $(\mathrm{p}<0.01)$ than in patients without developed muscular hearing: $2.04 \pm 0.14$ vs. $4.46 \pm 0.17$ points, respectively (Fig. 1, Table 1). Thus, in patients with group I, the average score of negative symptoms ranged from 1 point to 2.57 , which corresponds to very weak symptoms, whereas in patients in group II from 3.57 to 5.53 points (moderate to strong severity).

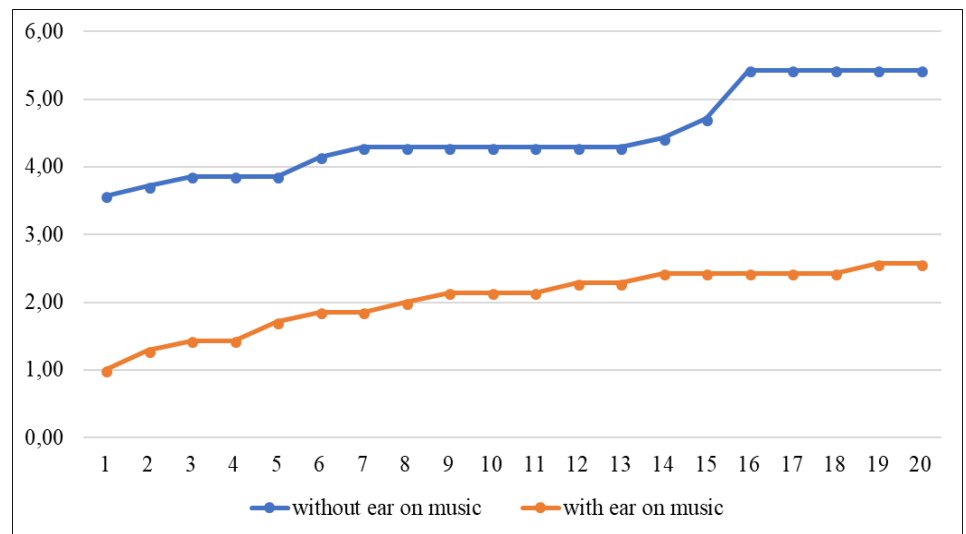

Fig. 1. Comparative characteristics of PANSS-NS subscale midpoints in patients with paranoid schizophrenia with ear on music $(n=20)$ and without ear on music $(n=20)$

Comparing the key indicators of the PANSS-NS subscale in patients with paranoid schizophrenia with advanced ear on music, it was found that the manifestations of "Violations of abstract thinking" (N5 - 2.35 \pm 0.15 points), "Violation of spontaneity and smoothness in the conversation" (N6 $2.30 \pm 0.15$ points) and "Stereotyped thinking" (N7 - 2.20 \pm 0.16 points). All these negative symptoms were observed in patients with ear on music from absence of severity ( 1 point) to weak one (3 points).

In patients with paranoid schizophrenia of group II (without ear on music), the highest severity of symptoms had the same negative symptoms of PANSS-NS subscale as in group I, but in a slightly different order: in the first place - "Stereotypical thinking" (N7 - 5.30 \pm 0.11 points), on the second - "Violation of spontaneity and smoothness in the conversation" (N6 - 5.20 \pm 0.14 points) and in the third - "Violation of abstract thinking" (N5 - 4.65 \pm 0.20 points). The degree of severity 
of these negative symptoms was from moderate (4 points) to very strong (6 points) for N5 and N6, and from strong (5 points) to very strong severity (6 points) at N7.

Table 1

Comparative assessment of the negative symptoms of the PANSS-NS subscale in patients with paranoid schizophrenia with advanced ear on music (group I) and without ear on music (group II) ( $\mathrm{M} \pm \mathrm{m}$, points)

\begin{tabular}{clrc}
\hline $\begin{array}{c}\text { No. neg. } \\
\text { symp. }\end{array}$ & \multicolumn{1}{c}{ Negative symptoms } & Group I & Group II \\
\hline N1 & Blurred passion & $1.75 \pm 0.10$ & $4.10 \pm 0.19^{*}$ \\
N2 & Emotional strangeness & $1.85 \pm 0.13$ & $4.05 \pm 0.18^{*}$ \\
N3 & Difficulties in communication: low contact, non-communicability & $1.95 \pm 0.15$ & $4.10 \pm 0.18^{*}$ \\
N4 & Passive-apathy social strangeness & $1.90 \pm 0.18$ & $3.80 \pm 0.21^{*}$ \\
N5 & Violation of abstract thinking & $2.35 \pm 0.15$ & $4.65 \pm 0.20^{*}$ \\
N6 & Violation of spontaneity and smoothness in the conversation & $2.30 \pm 0.15$ & $5.20 \pm 0.14^{*}$ \\
N7 & Stereotyped thinking & $2.20 \pm 0.16$ & $5.30 \pm 0.11^{*}$ \\
& In average & $2.04 \pm 0.14$ & $4.46 \pm 0.17$
\end{tabular}

Note: $*$ - the presence of a reliable $(p<0.01)$ difference between the indicators

The minimum mean scores for negative symptoms in group I (with ear on music) were present when evaluating the "Blurred passion" ( $\mathrm{N} 1-1.75 \pm 0.10$ points, from 1 to 2 points), in patients in group II - when evaluating "Passive-apathy social strangeness" (N4 - 3.80 \pm 0.21 points, from 2 to 5 points).

The analysis of the distribution of points of negative symptoms of PANSS-NS subscale in patients with a diagnosis of paranoid schizophrenia of group I (Table 2) showed that most of the patients with ear on music were evaluated at 2 points $-54.29 \pm 4.21 \%$ of the subjects $(\mathrm{p}<0.05$ compared with the proportion of patients with 1 point). The condition of each fourth patient $(25.00 \pm 3.66 \%, \mathrm{p}<0.05$ with severity of 2 points) corresponded to weak severity (3 points), and in each fifth $(20.71 \pm 3.43 \%)$ expressiveness negative symptoms were absent (1 point).

The lack of expressiveness (1 point) was most common in N4 "Passive-apathy social strangeness" - 35.00 $\pm 10.67 \%$ of patients, very weak severity ( 2 points) - for N1 "Blurred passion" $-75.00 \pm 9.68 \%$ of patients $(\mathrm{p}<0.05$ with the proportion of negative symptoms 1 and 3 points), weakness ( 3 points) - for N5 $-45.00 \pm 11.12 \%$ of patients ( $\mathrm{p}<0.05$ with the proportion of negative symptoms 1 point )

Table 2

Distribution of the points of negative symptoms in patients of group I $\left(\mathrm{P} \pm \mathrm{m}_{\mathrm{p}}, \%\right)$

\begin{tabular}{ccccccc}
\hline \multirow{2}{*}{$\begin{array}{c}\text { No. } \text { neg. } \\
\text { symp. }\end{array}$} & \multicolumn{5}{c}{ Number of patients with negative symptoms in: } \\
\cline { 2 - 7 } & abs. data & $\mathbf{P} \pm \mathbf{m}_{\mathbf{p}}, \mathbf{\%}$ & abs. data & $\mathbf{P} \pm \mathbf{m}_{\mathbf{p}}, \boldsymbol{\%}$ & abs. data & P $\pm \mathbf{m}_{\mathbf{p}}, \boldsymbol{\%}$ \\
\hline N1 & 5 & $25.00 \pm 9.68$ & 15 & $75.00 \pm 9.68^{*}$ & 0 & $0.00^{* \#}$ \\
N2 & 5 & $25.00 \pm 9.68$ & 13 & $65.00 \pm 10.67^{*}$ & 2 & $10.00 \pm 6.71^{\#}$ \\
N3 & 5 & $25.00 \pm 9.68$ & 11 & $55.00 \pm 11.12^{*}$ & 4 & $20.00 \pm 8.94^{\#}$ \\
N4 & 7 & $35.00 \pm 10.67$ & 8 & $40.00 \pm 10.95$ & 5 & $25.00 \pm 9.68$ \\
N5 & 2 & $10.00 \pm 6.71$ & 9 & $45.00 \pm 11.12^{*}$ & 9 & $45.00 \pm 11.12^{*}$ \\
N6 & 2 & $10.00 \pm 6.71$ & 10 & $50.00 \pm 11.18^{*}$ & 8 & $40.00 \pm 10.95$ \\
N7 & 3 & $15.00 \pm 7.98$ & 10 & $50.00 \pm 11.18^{*}$ & 7 & $35.00 \pm 10.67^{\#}$ \\
Total & 29 & $20.71 \pm 3.43$ & 76 & $54.29 \pm 4.21^{*}$ & 35 & $25.00 \pm 3.66^{\#}$
\end{tabular}

Note: *-existing $(p<0.05)$ difference with the percentage of marks "1 point"; ${ }^{*}$ - present $(p<0.05)$ difference with the share of marks "2 points" 


\section{Discussion}

In the analysis of the distribution of points of negative symptoms of PANSS-NS subscale in patients with paranoid schizophrenia of group II (Table 3), it was found that in more than $70 \%$ of cases the condition of a patient without ear on music was assessed as moderate (4 points) and strongly expressed ( 5 scores $)-37.86 \pm 4.10 \%$ and $33.57 \pm 3.99 \%$ of the subjects respectively $(\mathrm{p}<0.05$ versus the proportion of patients with a grade assessed at 6 points). The condition of each seventh patient (14.29 $\pm 2.96 \%$ ) was very strong (6 points), one eighth $(12.86 \pm 2.83 \%)$ - weak (3 points). Only in two patients $(1.43 \pm 1.00 \%)$ the severity of the negative symptoms was very weak (2 points at N4 - passive-apathy social isolation).

\section{Table 3}

Structure of distribution of points of negative symptoms in patients of group II ( $\left.\mathrm{P} \pm \mathrm{m}_{\mathrm{p}}, \%\right)$

\begin{tabular}{|c|c|c|c|c|c|c|}
\hline \multirow{2}{*}{ No. neg. symp. } & \multirow{2}{*}{$\mathbf{P} \pm \mathbf{m}_{\mathbf{p}}$} & \multicolumn{5}{|c|}{ Number of patients with negative symptoms in: } \\
\hline & & 2 points & 3 points & 4 points & 5 points & 6 points \\
\hline \multirow{2}{*}{ N1 } & abs. & 0 & 5 & 9 & 5 & 1 \\
\hline & $\%$ & 0 & $25.00 \pm 9.68$ & $45.00 \pm 11.12 *$ & $25.00 \pm 9.68$ & $5.00 \pm 4.87$ \\
\hline \multirow{2}{*}{ N2 } & abs. & 0 & 5 & 10 & 4 & 1 \\
\hline & $\%$ & 0 & $25.00 \pm 9.68$ & $50.00 \pm 11.18^{*}$ & $20.00 \pm 8.94$ & $5.00 \pm 4.87$ \\
\hline \multirow{2}{*}{ N3 } & abs. & 0 & 4 & 11 & 4 & 1 \\
\hline & $\%$ & 0 & $20.00 \pm 8.94$ & $55.00 \pm 11.12^{*}$ & $20.00 \pm 8.94$ & $5.00 \pm 4.87$ \\
\hline \multirow{2}{*}{ N4 } & abs. & 2 & 4 & 9 & 5 & 0 \\
\hline & $\%$ & $10,00 \pm 6,71$ & $20.00 \pm 8.94 *$ & $45.00 \pm 11.12 *$ & $25.00 \pm 9.68^{*}$ & 0.00 \\
\hline \multirow{2}{*}{ N5 } & abs. & 0 & 0 & 12 & 3 & 5 \\
\hline & $\%$ & 0 & 0 & $60.00 \pm 10.95^{*}$ & $15.00 \pm 7.98$ & $25.00 \pm 9.68$ \\
\hline \multirow{2}{*}{ N6 } & abs. & 0 & 0 & 2 & 12 & 6 \\
\hline & $\%$ & 0 & 0 & $10.00 \pm 6.71$ & $60.00 \pm 10.95^{*}$ & $30.00 \pm 10.25$ \\
\hline \multirow{2}{*}{ N7 } & abs. & 0 & 0 & 0 & 14 & 6 \\
\hline & $\%$ & 0 & 0 & 0 & $70.00 \pm 10.25^{*}$ & $30.00 \pm 10.25$ \\
\hline \multirow{2}{*}{$\Sigma$} & abs. & 2 & 18 & 53 & 47 & 20 \\
\hline & $\%$ & $1,43 \pm 1,00$ & $12.86 \pm 2.83$ & $37.86 \pm 4.10^{*}$ & $33.57 \pm 3.99 *$ & $14.29 \pm 2.96$ \\
\hline
\end{tabular}

Note: *-existing $(p<0.05)$ difference with the share of marks "6 points"

The weakness (3 points) of negative symptoms was almost identical to N1, N2, N3, N4 from $20.00 \pm 8.94 \%$ to $25.00 \pm 9.68 \%$ of patients without ear on music. The moderate severity (4 points) was characteristic of N1 "Blurred passion" $-60.00 \pm 10.95 \%$ of patients $(\mathrm{p}<0.05$ with a share of negative symptoms of 6 points). At the same time, this degree of severity of symptoms was characterized by the fact that patients often resorted to a particular way of thinking, experienced difficulties in the interpretation of some abstract concepts, the allocation of the most characteristic feature of the phenomenon or object.

The highest proportion $(70.00 \pm 10.25 \%, \mathrm{p}<0.05$ with a share of negative symptoms of 6 points) of patients with paranoid schizophrenia without ear on music had a strong severity (5 points) of rigidity and stereotyping of thinking (N7), which manifested itself in that , despite the doctor's opposition, the conversation was limited to only two or three predominant themes.

The extreme degree of severity (6 points) was the same (30.00 $\pm 10.25 \%)$, which was inherent in the negative symptoms of N6 and N7, which was manifested by changes in stereotyped thinking and disrupted spontaneity and smoothness in the conversation: in thinking, behavior and conversation of the patient dominated by constantly repeated ideas or individual phrases, the patient's responses were limited to a few words or short phrases aimed at ending the conversation (for example: "I do not know", "I can not talk about it"), which led to inadequate and sharp restriction of contact with a doctor. 


\section{Conclusions}

1. The obtained data prove a significant correlation between the presence of ear on music and the forms and degree of severity of negative symptoms in paranoid schizophrenia.

2. Definition of patients with schizophrenia in the «ear on music» in the early stages of the disease can be considered as a proxy criterion for the formation of negative symptoms.

3. It can be predicted that the presence of ear on music has a link with the biological constitutional features (biological markers) that determine the form and severity of deficiency -negative manifestations in the development of schizophrenia.

\section{References}

[1] Nielzen, S. (2007). An objective diagnostic decision support for schizophrenia. European Psychiatry, 22, 86. doi: 10.1016/j.eurpsy.2007.01.1192

[2] Yurchenko, O. M. (2016). Clinico-psychopathological and psychodiagnostic characteristics of patients with paranoid schizophrenia and its diagnostic value. World of Medicine and Biology, 4 (58), 87-92.

[3] Yurchenko, O. M. (2016). Socio-demographic characteristics of patients with paranoid schizophrenia and its diagnostic value. Ukrainian Journal of Psychoneurology, 24 (2 (87)), 101-106.

[4] World Health Organization. International Classification of Diseases (ICD). (2010). Available at: http://www.who.int/classifications/icd/ICD10Volume2_en_2010.pdf

[5] Garcia-Portilla, M. P., Garcia-Alvarez, L., Saiz, P. A., Al-Halabi, S., Bobes-Bascaran, M. T., Bascaran, M. T. et. al. (2015). Psychometric evaluation of the negative syndrome of schizophrenia. European Archives of Psychiatry and Clinical Neuroscience, 265 (7), 559-566. doi: 10.1007/s00406-015-0595-z

[6] García-Portilla, M. P., Bobes, J. (2013). The new challenge in identifying the negative syndrome of schizophrenia. Revista de Psiquiatría y Salud Mental (English Edition), 6 (4), 141-143. doi: 10.1016/ j.rpsmen.2013.10.001

[7] Khan, A., Lindenmayer, J.-P., Opler, M., Yavorsky, C., Rothman, B., Lucic, L. (2013). A new Integrated Negative Symptom structure of the Positive and Negative Syndrome Scale (PANSS) in schizophrenia using item response analysis. Schizophrenia Research, 150 (1), 185-196. doi: 10.1016/j.schres.2013.07.007

[8] Khmara, N. V., Skugarevsky, O. A. (2018). Hostile attributive style and aggressive tendencies in individuals with schizophrenia, assessment tools. Medical Journal, 1, 142-145.

[9] Simonov, A. N., Abramova, L. I. (2016). The effect of scaling the PANSS scale on the evaluation of the effectiveness of antipsychotic therapy. Psychiatry, 1 (69), 34-39.

[10] Anderson, A. E., Reise, S. P., Marder, S. R., Mansolf, M., Han, C., Bilder, R. M. (2017). Innov. Clin. Neurosci Disparity between General Symptom Relief and Remission Criteria in the Positive and Negative Syndrome Scale (PANSS). A Post-treatment Bifactor Item Response Theory Model, 14 (11-12), 41-53.

[11] Nielzen, S., Kallstrand, J., Larsson, L., Olsson, O. (2004). Klinisk psykoakustik kan ge objektiv diagnos vid schizofreni (Clinical psychoacoustics can support an objective diagnosis of schizophrenia). Lakartidningen, 101, 1376-1379.

[12] Van Erp, T. G. M., Preda, A., Nguyen, D., Faziola, L., Turner, J., Bustillo, J. et. al. (2014). Converting positive and negative symptom scores between PANSS and SAPS/SANS. Schizophrenia Research, 152 (1), 289-294. doi: 10.1016/j.schres.2013.11.013

[13] Anderson, A., Wilcox, M., Savitz, A., Chung, H., Li, Q., Salvadore, G. et. al. (2015). Sparse factors for the positive and negative syndrome scale: Which symptoms and stage of illness? Psychiatry Research, 225 (3), 283-290. doi: 10.1016/j.psychres.2014.12.025

[14] Khan, A., Lindenmayer, J. P., Opler, M., Kelley, M. E., White, L., Compton, M. et. al. (2014). The evolution of illness phases in schizophrenia: A non-parametric item response analysis of the Positive and Negative Syndrome Scale. Schizophrenia Research: Cognition, 1 (2), 53-89. doi: 10.1016/j.scog.2014.01.002

[15] Krekels, E., Novakovic, A., Vermeulen, A., Friberg, L., Karlsson, M. (2017). Item Response Theory to Quantify Longitudinal Placebo and Paliperidone Effects on PANSS Scores in Schizophrenia. CPT: Pharmacometrics \& Systems Pharmacology, 6 (8), 543-551. doi: 10.1002/psp4.12207

[16] Reise, S. P. (2012). The Rediscovery of Bifactor Measurement Models. Multivariate Behavioral Research, 47 (5), 667-696. doi: 10.1080/00273171.2012.715555

[17] Marder, S. R., Daniel, D. G., Alphs, L., Awad, A. G., Keefe, R. S. E. (2011). Methodological Issues in Negative Symptom Trials. Schizophrenia Bulletin, 37 (2), 250-254. doi: 10.1093/schbul/sbq161 
[18] Obermeier, M., Schennach-Wolff, R., Meyer, S., Moller, H.-J., Riedel, M., Krause, D., Seemuller, F. (2011). Is the PANSS used correctly? A systematic review. BMC Psychiatry, 11 (1). doi: 10.1186/ 1471-244x-11-113

[19] Nielzen, S. (2008). Psychoacoustics \& Schizophrenia. J. Der Nervenarzt, 79, 193.

[20] Nielzen, S., Kallstrand, J., Larsson, L. (2004). Clinical psychoacoustics can support an objective diagnosis of schizophrenia. J. Lakartidningen, 101, 15-16.

[21] Besh, L. V., Matsiura, O. I., Novikevych, S. Z., Yanchinska, O. V, Gutor, T. H. (2014). Analysis of the sensitization structure of children with seasonal allergies. Problems of clinical pediatrics, 1 (23), 23-32.

\title{
MEDICAL AND SOCIAL CHARACTERISTICS OF PHYSICIANS ATTENDING POSTGRADUATE TRAINING COURSES (SOCIAL SURVEY)
}

\author{
Orest Sichkoriz \\ Department of Pediatric Infectious Diseases \\ Danylo Halytsky Lviv National Medical University \\ 69 Pekarska str., Lviv, Ukraine, 79010 \\ sichkorizoye@gmail.com
}

\begin{abstract}
The paper studies professional, social and psychological aspects concerned with a practical activity of physicians referred to attend postgraduate training courses at Danylo Halytsky Lviv National Medical University.

Aim. To develop the recommendations on the improvement in the system of postgraduate medical education under the conditions of general reform in the health care system.

The research was done by the survey method in the form of standardized (formalized) interview that was applied as the main approach to the process of collecting social and psychological information.The survey included 823 physicians referred to attend postgraduate training courses at Danylo Halytsky Lviv National Medical University. The working experience of postgraduate course attendants was the following: up to 5 years $-25.39 \pm 1.52 \%, 5-10$ years $-21.39 \pm 1.43 \%, 11-15$ years $-11.79 \pm 1.12 \%, 16-20$ years $9.96 \pm 1.04 \%, 21-30$ years $-16.89 \pm 1.31 \%$, more than 30 years $-14.58 \pm 1.23 \%$.

The majority of questioned medical workers ( $74.24 \pm 1.52 \%)$ feel calm and happy at their working place. However, the received data indicates that $23.09 \pm 1.47 \%$ of the responders feel disturbance and $1.94 \pm 0.48 \%$ experience fear at work. The analysis of the research results allowed differentiating five sharp problems which are very topical and significant at the medical institution where the physicians have been performing their practice. They can be ranged in the following way: the job compensation ( $42.93 \pm 2.09 \%)$, absence of modern medical equipment $(26.65 \pm 1.87 \%$ ), organization of the working process $(22.90 \pm 1.78 \%)$, reorganization ( $7.69 \pm 1.13 \%)$, extra documentation $(7.33 \pm 1.10 \%)$. The carried out survey permitted to determine the psychological atmosphere at medical institutions there the course attendants have been practicing. The conflicts are not a characteristic feature of medical institutions, since almost half of the responders indicated the absence of conflicts with higher managers ( $52.86 \pm 1.74 \%)$, direct managers $(43.01 \pm 1.73 \%)$, subordinate personnel $(43.38 \pm 1.73 \%)$. This index is somewhat lower concerning the colleagues and patients. It amounts for $36.33 \pm 1.68 \%$ and $33.17 \pm 1.64 \%$ respectively.

The physicians practicing in medicine and prevention as well as dentistry branches are most disturbed by the lack of financial sources. More than a half of responders $(73.86 \pm 2.70 \%)$ indicated it by their answers. Other responses included the absence of perspectives $-68.18 \pm 2.87 \%$, extreme, stressful living conditions $-25.38 \pm 2.68 \%$, personal present health status $-20.08 \pm 2.47 \%$, personal lack of confidence $-9.47 \pm 1.80 \%$ (the number of responses was not restricted).

The carried out work has showed the necessity of introducing the specialized course "State medical policy". It should be aimed at delivering the information on the status, perspectives, reforming changes and the expected outcomes resulting from these factors in the branch of medicine. In order to decrease the negative influence of the professional burnout, it is recommended to plan the specialized training classes that are directed on the prevention of the listed above phenomena.
\end{abstract}

Keywords: postgraduate education, standardized interview, medical and social aspects, health care. 